\title{
Evaluation of anterior segment parameters using Scheimpflug technology during the Valsalva maneuver in patients with keratoconus
}

\author{
Avaliação de parâmetros do segmento anterior usando a tecnologia Scheimpflug durante \\ a manobra de Valsalva em pacientes com ceratocone
}

Yusuf Koçluk ${ }^{1}$, Emine Alyamaç Sukgen ${ }^{1}$, Selim CevherR ${ }^{1}$

\begin{abstract}
Purpose: This study aimed to explore the effects of the Valsalva maneuver (VM) on ectatic corneas during anterior segment tomography scans using a Scheimpflug camera.

Methods: This prospective observational study included 100 eyes of 50 patients with bilateral keratoconus (KC). Anterior segment tomography was first performed when the patients were in a resting position and immediately repeated as the participant performed VM. Scheimpflug images were taken using a Pentacam ${ }^{\circledR}$. Results: The mean age of the participants was $24.14 \pm 6.59$ years. Of the 100 eyes included in the study, $7 \%$ had stage $1 \mathrm{KC}, 47 \%$ had stage $2 \mathrm{KC}, 32 \%$ had stage $3 \mathrm{KC}$ and $14 \%$ had stage $4 \mathrm{KC}$. The indices of KC were not significantly affected by VM. Similarly, no statistically significant differences were found between the stages of $\mathrm{KC}$, or with the mean pachymetric progression index during VM. Pupil diameter showed a statistically significant increase during VM ( $p=0.017)$. There was a statistically significant decrease in the anterior chamber angle measurement during VM $(p=0.001)$. Maximum curvature power in the front of the cornea decreased more during VM in stage 4 KC than for the other stages ( $p=0.014)$.

Conclusions: No changes associated with VM were found in the KC indices or the stage of the disease. However, an increase in pupil diameter and a decrease in anterior chamber angle value were found. These changes were comparable to values obtained from previous studies performed on normal corneas.
\end{abstract}

Keywords: Anterior chamber/physiology; Keratoconus; Valsalva maneuver/physiology; Corneal topography

\section{RESUMO}

Objetivo: Este estudo tem como objetivo explorar os efeitos da manobra de Valsalva (VM) na córnea ectásica durante a varredura tomográfica do segmento anterior usando a câmera de Scheimpflug.

Métodos: Foi conduzido estudo observacional, prospectivo envolvendo 100 olhos de 50 pacientes que apresentavam ceratocone (KC) bilateral. Tomografia do segmento anterior foi realizada inicialmente quando os pacientes estavam em posição de repouso e imediatamente depois, no curso de VM. Imagens de Scheimpflug foram feitas usando Pentacam ${ }^{\circledR}$.

Resultados: A média de idade dos participantes foi 24,14 $\pm 6,59$ anos de idade. Dos olhos incluídos no estudo, 7\% apresentava KC estágio 1,47\% apresentava estágio 2,32\% apresentava estágio 3, e 14\% apresentava estágio 4. Indices de KC não foram significativamente afetadas pela VM. Não houve diferenças estatisticamente significativas com o estágio do KC, e o índice médio de progressão paquimétrica durante a VM. O diâmetro da pupila (PD) mostrou aumento estatisticamente significativo durante a VM $(p=0,017)$. Houve diminuição estatisticamente significativa na medida do ângulo da câmara anterior durante a VM $(p=0,001)$. O poder máximo de curvatura anterior da córnea no KC estágio 4 diminuiu mais do que os outros estágios durante o VM ( $p=0,014)$.

Conclusões: Não foram encontradas alterações nos índices KC e no estágio da doença por causa da VM. Verificou-se que houve aumento na PD e uma diminuição no valor do ângulo da câmara anterior. Estas alterações foram comparáveis aos valores obtidos a partir de estudos realizados em córneas normais.

Descritores: Câmara anterior/fisiologia; Ceratocone; Manobra de Valsava/fisiologia; Topografia da córnea

\section{INTRODUCTION}

Keratoconus (KC) is a noninflammatory eye condition characterized by progressive corneal ectasia, myopia, and irregular astigmatism, generally with bilateral involvement. The etiology and progression of keratoconus have been closely linked to genetic factors, which appear to be multifactorial. However, the majority of cases are not linked to genetic factors ${ }^{(1,2)}$. It is important to detect progression in $\mathrm{KC}$ before making collagen cross-linking (CXL).

The Valsalva maneuver (VM) is an attempt at a powerful exhalation against a closed airway. VM is frequently performed during normal daily activities: examples include lifting heavy items, performing physical exercise, vomiting, and coughing. Various physiological changes happen during these activities, including elevated blood pressure, increased intrathoracic pressure, increased peripheral venous pressure, and stimulation of the peripheral sympathetic system ${ }^{(3-5)}$. The clinical consequences of VM may have some effects on the anterior chamber, such as a significant narrowing of the iridocorneal angle and a shallowing of the central anterior chamber ${ }^{(6,7)}$. When patients hold their breath and perform an involuntary VM during ophthalmological examinations, the progression of ectasia could be measured incorrectly.

The aim of the present study was to explore the effects of VM on ectatic corneas during corneal topography scans using a Scheimpflug camera.

\section{METHODS}

This prospective observational study involved 100 eyes of 50 patients with bilateral KC. Institutional Review Board approval was obtained, and the study was conducted according to the ethical standards of the Declaration of Helsinki.
Submitted for publication: February 17, 2016

Accepted for publication: June 1, 2016

${ }^{1}$ Ophthalmology Clinic, Adana Numune Training and Research Hospital, Adana, Turkey.
Funding: No specific financial support was available for this study.

Disclosure of potential conflicts of interest: None of the authors have any potential conflict of interest to disclose.

Corresponding author: Yusuf Koçluk. Eye Department. Adana Numune Training and Research Hospital - Yüreğir, Adana, 06520 - Turkey - E-mail: kocluk99@gmail.com

Approved by the following research ethics committee: Adana Numune Training and Research Hospital (\# 2015/210). 
Patients with corneal ectatic disease other than KC or other ocular surface and/or intraocular pathology, patients who had undergone any previous eye surgery, and patients who received CXL were excluded from the study. In addition, patients with any kind of systemic disease that could make VM intolerable, and users of anticoagulants, were also excluded. VM was performed during the examination by blowing through a mouthpiece attached to a manometer. Expiratory pressure ranged between 35 and $40 \mathrm{mmHg}^{(8)}$.

An anterior segment analyzer, Pentacam (Oculus Optikgerate, Wetzlar, Germany), utilizes the Scheimpflug principle in photography with a view to capturing slit images and producing a variety of data in a non-contact fashion. The system includes a rotating Scheimpflug camera and a light source that emits UV-free blue light with a wavelength of $475 \mathrm{~nm}^{(6)}$. This system enables the diagnosis of KC, as well as grading the condition and disease monitoring.

Corneal topography was initially performed with the participant in a resting position, immediately followed by repeating the procedure while the patient performed VM. The same ophthalmologist (Y.K) performed all the measurements. Topography images were taken using the Pentacam, which enabled images to be taken of the anterior and posterior surfaces of the cornea and iris, and of the anterior and posterior surfaces of the lens in a movable virtual eye ${ }^{(9)}$. After positioning the participant's head in a chin rest and head rest, the participant was asked to fixate on the center of the blue slit light. The joystick was adjusted by the examiner until appropriate alignment was obtained. A $9.00 \mathrm{~mm}$ diameter spherical reference, was used in elevation maps. The evaluated parameters are presented in table 1.

The results were analyzed using SPSS 16.0 software for Windows (SPSS Inc., Chicago, IL). Data are presented as mean \pm standard deviation (SD). Parameters studied before and during VM were compared using paired sample t-tests, and a general linear model (repeated measures) was used for analyzing the parameters according to the stage of KC. A p-value of $<0.05$ was considered to indicate statistical significance.

\section{RESULTS}

The mean age of the participants with $\mathrm{KC}$ in both eyes was found to be $24.14 \pm 6.59$ years. Of the 50 participants, 27 (54\%) were female and 23 (46\%) were male. Both of the participants' eyes were included in the study. Of the eyes included in the study, $7 \%$ were at stage $1 \mathrm{KC}$, $47 \%$ were at stage $2 \mathrm{KC}, 32 \%$ were at stage $3 \mathrm{KC}$, and $14 \%$ were at stage $4 \mathrm{KC}$.

The indices of KC (ISV, IVA, KI, CKI, IHA, IHD, and Rmin) were not significantly affected by performing $V M$ and did not change according to the stage of KC. Similarly, no statistically significant effects were found for the stage of KC, D value, and the average pachymetric progression index over VM. Table 2 presents results showing the effects of VM on anterior segment parameters. When the effects of the KC stage on the parameters were compared, there was a greater decline during VM in CFS Km, Kmax, and D in KC stage 4 cases. These differences were statistically significant with respect to the stage of KC (Table 2). The differences in the other parameters before and during VM did not change with the stage of the KC.

Pupil diameter increased to a statistically significant degree during VM ( $p=0.017)$. Conversely, there was a statistically significant decrease in the angle value during VM ( $p=0.001)$. Although the $x$ - and $y$-coordinates of Kmax changed sides ( $p=0.007, p=0.006)$, the change in Kmax value was not statistically significant $(p=0.107)$. Changes in other anterior segment parameters were also not statistically significant.

\section{DISCUSSION}

$\mathrm{KC}$ is a degenerative disease of the cornea characterized by stromal thinning and conical ectasia(1). KC is usually caused to progress by increased keratometry, irregular astigmatism, and decreased corneal thickness ${ }^{(10-12)}$. The progression of ectasia was diagnosed based on the corneal tomography and topographic changes. These changes included progressive elevation of the posterior and/or anterior surface, progressive corneal thinning at the thinnest point, and an increase in corneal anterior keratometry steepening with an irregular astigmatism in the cone area.

Choi et al. ${ }^{(13)}$ reported a study in which $25 \%$ of eyes were found to have progression in central keratometry of at least $1.5 \mathrm{D}$, according to measurements taken by computerized videokeratography (Orbscan II) over a mean of 3.5 years, with a median time to progression of 12 years. Progression in KC disease is determined by a comparison of topographic measurements taken at different times. The present study evaluated whether inaccurate positive or negative results occurred due to VM performed even involuntarily during the measurements. A decline in the value of Kmax was observed during VM in stage $4 \mathrm{KC}$, which could be interpreted mistakenly as regression of the disease. Thankfully, CXL for progression is not recommended in these advanced KC patients.

\section{Table 1. The evaluated parameters}

\begin{tabular}{|c|c|}
\hline Anterior segment parameter & Description of parameter \\
\hline CFS Km & $\begin{array}{l}\text { Mean curvature power in the central } 3 \mathrm{~mm} \\
\text { cornea front surface (CFS) }\end{array}$ \\
\hline CFS Astig & Astigmatism on the CFS \\
\hline CFS Q-val $\left(30^{\circ}\right)$ & $\begin{array}{l}\text { Asphericity in the central } 6 \mathrm{~mm} \text { of the CFS. A } \\
\text { normal Q-val was considered to be between } \\
0 \text { and - } 1(10) \text {. }\end{array}$ \\
\hline CBS Km & $\begin{array}{l}\text { Mean curvature power in the central } 3 \mathrm{~mm} \text { of } \\
\text { the cornea back surface (CBS) }\end{array}$ \\
\hline CBS Astig & Astigmatism on the CBS \\
\hline CBS Q-val $\left(30^{\circ}\right)$ & Asphericity in the central $6 \mathrm{~mm}$ on the CBS \\
\hline PA & Corneal thickness at the apex \\
\hline TLP & $\begin{array}{l}\text { Thinnest location pachy in the central } 9 \mathrm{~mm} \\
\text { of the cornea }\end{array}$ \\
\hline Kmax & $\begin{array}{l}\text { Maximum curvature power in front of cornea. } \\
\text { The position of the Kmax from the apex is } \\
\text { shown with Kmax } x \text { - and Kmax } y \text {-coordinates }\end{array}$ \\
\hline$C D$ & Corneal diameter \\
\hline CV & Corneal volume \\
\hline ChV & Chamber volume \\
\hline PD & Pupil diameter \\
\hline AC Depth & Central anterior chamber depth \\
\hline Angle & Mean value of the anterior chamber volume \\
\hline ISV & Index of surface variance \\
\hline IVA & Index of vertical asymmetry \\
\hline $\mathrm{KI}$ & KC index \\
\hline CKI & Center KC index \\
\hline IHA & Index of height asymmetry \\
\hline IHD & Index of height decentration \\
\hline Rmin & Minimum value of the curvature of the cornea \\
\hline TKC & $\begin{array}{l}\text { KC stage is displayed. The stage of the disease } \\
\text { is classified according to the Amsler classifica- } \\
\text { tion by the software package (11) }\end{array}$ \\
\hline Avg. PI & $\begin{array}{l}\text { Pachymetric progression index average. } 1.0 \text { is } \\
\text { the progression index for normal eyes. }\end{array}$ \\
\hline D & $\begin{array}{l}\text { Total deviation value that the combination } \\
\text { of the pachymetric graphs and indices and } \\
\text { elevation maps which utilize the enhanced } \\
\text { reference sphere provided the Belin/Ambrosio } \\
\text { Enhanced Ectasia Display has increased } \\
\text { sensitivity and specificity in the screening of } \\
\text { patients for ectasia }\end{array}$ \\
\hline
\end{tabular}


Table 2. Anterior segment parameters in the resting position and during VM in KC patients

\begin{tabular}{|c|c|c|c|c|}
\hline $\begin{array}{l}\text { Anterior segment } \\
\text { parameters }{ }^{\&}\end{array}$ & $\begin{array}{c}\text { Resting } \\
\text { position } \\
\text { (mean } \pm \text { S.D) }\end{array}$ & $\begin{array}{c}\text { Valsalva } \\
\text { maneuver } \\
(\text { mean } \pm \text { S.D) }\end{array}$ & $\begin{array}{c}\mathbf{p} \\
\text { value* }\end{array}$ & $\begin{array}{l}\text { p value** } \\
\text { according } \\
\text { to KC stage }\end{array}$ \\
\hline \multicolumn{5}{|l|}{ Cornea front surface (CFS) } \\
\hline CFS Km & $49.97 \pm 4.97$ & $49.68 \pm 4.70$ & 0.065 & 0.018 \\
\hline CFS Astig & $4.54 \pm 2.56$ & $4.53 \pm 2.72$ & 0.915 & 0.198 \\
\hline CFS Q-val & $-1.09 \pm 0.81$ & $-0.96 \pm 0.59$ & 0.620 & 0.563 \\
\hline \multicolumn{5}{|l|}{ Cornea backsurface (CBS) } \\
\hline CBS Km & $-7.63 \pm 0.95$ & $-7.48 \pm 1.15$ & 0.078 & 0.291 \\
\hline CBS Astig & $0.93 \pm 0.46$ & $0.89 \pm 0.48$ & 0.226 & 0.456 \\
\hline CBS Q-val & $-1.03 \pm 0.48$ & $-1.37 \pm 1.60$ & 0.067 & 0.345 \\
\hline \multicolumn{5}{|l|}{ Corneal thickness } \\
\hline PA (apex) & $447.02 \pm 61.47$ & $448.48 \pm 59.38$ & 0.405 & 0.131 \\
\hline TLP (thinnest) & $434.17 \pm 65.44$ & $433.64 \pm 60.28$ & 0.679 & 0.439 \\
\hline \multicolumn{5}{|l|}{ Other parameters } \\
\hline Kmax & $58.05 \pm 8.06$ & $57.75 \pm 7.61$ & 0.107 & 0.014 \\
\hline Kmax $x$-coordinate & $0.09 \pm 0.43$ & $-0.03 \pm 0.38$ & 0.007 & 0.167 \\
\hline Kmax $y$-coordinate & $-0.52 \pm 1.18$ & $-0.74 \pm 1.06$ & 0.006 & 0.231 \\
\hline CD (cornea diameter) & $11.91 \pm 0.41$ & $11.91 \pm 0.40$ & 0.924 & 0.897 \\
\hline CV (cornea volume) & $58.19 \pm 3.91$ & $58.03 \pm 4.06$ & 0.108 & 0.175 \\
\hline ChV (chamber volume & $193.44 \pm 24.32$ & $193.68 \pm 28.33$ & 0.770 & 0.234 \\
\hline PD (pupil diameter) & $3.24 \pm 0.84$ & $3.34 \pm 0.79$ & 0.017 & 0.557 \\
\hline AC depth & $3.81 \pm 0.34$ & $3.80 \pm 0.02$ & 0.673 & 0.612 \\
\hline Angle & $40.60 \pm 5.41$ & $39.13 \pm 6.57$ & 0.001 & 0.433 \\
\hline TKC (stage of KC) & $2.56 \pm 0.86$ & $2.53 \pm 0.08$ & 0.259 & - \\
\hline Avg. PI & $2.85 \pm 2.08$ & $2.79 \pm 1.81$ & 0.344 & 0.197 \\
\hline D & $10.69 \pm 5.91$ & $10.51 \pm 5.81$ & 0.352 & 0.004 \\
\hline
\end{tabular}

${ }^{*}=$ paired samples $t$ test $;{ }^{* *}=$ general linear model test for four KC stages (differences between KC stage 1,2, 3, and 4 groups); ${ }^{2}=$ see table 1 for a description of parameters. $\mathrm{KC}=$ keratoconus; $\mathrm{VM}=$ Valsalva maneuver

Although several studies have tried to investigate the factors that help determine the prognosis, it remains a challenge to predict progression at the time of diagnosis in a specific patient. However, some predictors of progression include a higher cylinder and keratometry (as measured by topography), thinnest pachymetry, and shorter disease duration ${ }^{(13-15)}$. As these topography parameters are compared between two measurements, those measurements should be performed under ideal conditions without bias from environmental factors. An inaccurate corneal topography could result in mistakes in the diagnosis of progression. Some patients may perform VM involuntarily during corneal topography. However, in this study performing VM did not result in any statistically significant changes in the KC progression indices.

Pekel et al., in their study involving measurements with a Pentacam system, found that AC depth and central corneal thickness in healthy individuals without $\mathrm{KC}$ decreased significantly with $\mathrm{VM}^{(8)}$. They also found that VM could affect corneal morphology and that it caused certain reversible changes in the keratometry. Our study also investigated whether there would be changes in KC patients; we found that PD, angle value, and the $x$ - and $y$-coordinates of Kmax changed. A similar study which evaluated normal corneas demonstrated an increase in $P D$ and decrease in $A C D^{(16)}$. The only organ related to the autonomic nervous system in the study was the pupi ${ }^{(17)}$. There was decreased vagal and increased peripheral sympathetic stimulation during VM, and the noted dilation could be explained by this. Narrowing of the anterior chamber and iridocorneal angle could be caused even by this mild dilation ${ }^{(18)}$
With subclinical disease, anterior curvature alone may not provide enough information to detect an early corneal abnormality. The goal of the Belin/Ambrosio Enhanced Ectasia Display was to combine elevation and pachymetric-based corneal evaluation in an all-inclusive display ${ }^{(19)}$. The present study found no statistically significant changes in $\mathrm{D}$ values, demonstrating early posterior ectatic changes during VM. However, D values in advanced KC have been found to exhibit more changes than in the other stages of KC, between, before, and during VM. These changes are not important in clinical practice because the D value is more important at the early stage of $\mathrm{KC}$.

Previous studies have demonstrated the effect of VM on healthy corneas ${ }^{(8,16)}$. However, this effect has not been studied in KC patient groups. Before the study was conducted, more anterior segment parameter changes were predicted in KC patients who had thinner and less rigid corneas than in VM studies mentioned. However, the present study found no anterior segment parameter changes that would affect stage changes and treatment plans for KC patients.

In conclusion, no changes were found in the KC indices and stage of the disease while participants were performing VM. Furthermore, it was found that there was an increase in PD and a decrease in angle, and these changes were similar to those from studies on normal corneas. The Kmax value in stage $4 \mathrm{KC}$ may decrease more during VM than in other stages.

\section{REFERENCES}

1. Rabinowitz YS. Keratoconus. Surv Ophthalmol. 1998;42(2):297-319.

2. Galvis V, Sherwin T, Tello A, Merayo J, Barrera R, Acera A. Keratoconus: an inflammatory disorder? Eye (Lond). 2015;29(7):843-59.

3. Falcao M, Vieira M, Brito P, Rocha-Sousa A, Brandão EM, Falcão-Reis FM. Spectral-domain optical coherence tomography of the choroid during valsalva maneuver. Am J Ophthalmol. 2012;154(4):687-92

4. Sihota R, Dada T, Aggarwal A, Srinivasan G, Gupta V, Chabra VK. Does an iridotomy provide protection against narrowing of the anterior chamber angle during Valsalva maneuvre in eyes with primary angle closure. Eye (Lond). 2008;22(3):389-93.

5. Zebrowska A, Gasior Z, Jastrzebski D. Cardiovascular effects of the Valsalva maneuver during static arm exercise in elite power lifting athletes. Adv Exp Med Biol. 2013:755: 335-42

6. Soleimani M, Hashemi H, Mehravaran S, Khabazkhoob M, Emamian MH, Shariati M, et al. Comparison of anterior segment measurements using rotating Scheimpflug imaging and partial coherence interferometry. Int J Ophthalmol. 2013:6(4):510-4.

7. Wang BS, Xiao L, Liu J, Dong N, Aung T. Dynamic changes in anterior segment morphology during the Valsalva maneuver assessed with ultrasound biomicroscopy. Invest Ophthalmol Vis Sci. 2012:53(11):7286-9.

8. Pekel G, Acer S, Yagci R, Kaya H, Pekel E. Impact of valsalva maneuver on corneal morphology and anterior chamber parameters. Cornea. 2014;33(3):271-3.

9. Huseynova T, Abdulaliyeva F, Lanza M. Comparison of Scheimpflug imaging parameters between steep and keratoconic corneas of Caucasian eyes. Clin Ophthalmol. 2016; 10:603-8.

10. Flynn TH, Sharma DP. Bunce C. Wilkins MR. Differential precision of corneal Pentacam HR measurements in early and advanced keratoconus. Br J Ophthalmol. 2015; pii: bjophthalmol-2015-307201.

11. Koçluk Y, Yalniz-Akkaya Z, Burcu A, Örnek F. Comparison of Scheimpflug imaging analysis of pellucid marginal corneal degeneration and keratoconus. Ophthalmic Res. 2015;53(1):21-7

12. Steinberg J, Ahmadiyar M, Rost A, Frings A, Filev F, Katz T, Linke SJ. Anterior and posterior corneal changes after crosslinking for keratoconus. Optom Vis Sci. 2014;91(2): 178-86.

13. Choi JA, Kim MS. Progression of keratoconus by longitudinal assessment with corneal topography. Invest Ophthalmol Vis Sci. 2012;53(2):927-35

14. McMahon TT, Edrington TB, Szczotka-Flynn L, Olafsson HE, Davis LJ, Schechtman KB; CLEK Study Group. Longitudinal changes in corneal curvature in keratoconus. Cornea. 2006;25(3):296-305

15. Kanellopoulos AJ, Asimellis G. Revisiting keratoconus diagnosis and progression classification based on evaluation of corneal asymmetry indices, derived from Scheimpflug imaging in keratoconic and suspect cases. Clin Ophthalmol. 2013;7:1539-48.

16. Mete A, Kimyon S, Uzun I, Kara N. Effects of Valsalva Maneuver on Ocular Biometric Parameters: Optical Low-Coherence Reflectometry Biometer Study. Semin Ophthalmol. 2015; Aug 21:1-4

17. Reulen JP, Marcus JT, van Gilst MJ, Koops D, Bos JE, Tiesinga G, et al. Stimulation and recording of dynamic pupillary reflex: The IRIS technique: part 2. Med Biol Eng Comput. 1988;26(1):27-32.

18. Marchini G, Pagliarusco A, Toscano A, Tosi R, Brunelli C, Bonomi L. Ultrasound biomicroscopic and conventional ultrasonographic study of ocular dimensions in primary angle closure glaucoma. Ophthalmology. 1998;105(11):2091-8.

19. Belin MW, Khachikian SS. Elevation based topography, screening for refractive surgery: USA: Highlights of Ophthalmology International; 2008. p.83-4. 